\title{
Galloping instabilities of Z-shaped shading louvers
}

\author{
Gustavo Alonso, Isabel Pérez-Grande and \\ José Meseguer
}

\begin{abstract}
Modern design of civil constructions such as office blocks, airport terminal buildings, factories, etc. incorporates more and more environmental considerations that lead to, amongst other elements, the use of glazed façades with shading devices to optimize energy consumption. These shading devices, normally slats or louvers, are very flexible structures exposed to the action of wind, and therefore aeroelastic effects such as galloping must be taken into account in their design. A typical cross-section for such elements is a Z-shaped profile made out of a central web and two side wings. The results of a parametric analysis based on static wind tunnel tests and performed on different Z-shaped louvers to determine translational galloping instability regions are presented in this paper.
\end{abstract}

\section{Keywords}

Galloping, Wind tunnel, Louvers

\section{Introduction}

The move towards sustainable development is leading designers in the direction of adopting the so-called passive design strategies. This means using construction design techniques to aid the natural heating or cooling of a building and to control the natural illumination due to sunlight. Such an approach has led to an increasing use of glass in the façade design of office buildings. The arguments that justify the heavily glazed office buildings as energy efficient structures are that increasing the area of glazing allows more day lighting, whereas reducing the area of glazing can reduce solar gain and glare.

Generally it is assumed that Venetian blinds or similar devices can assist in meeting those objectives. This is provided that, during dark or overcast periods, they are pulled up (in case they were retractable), or at least that slats are in the open position, and that during sunny periods, when cooling or shading from the sun is required, they are pulled down and their slats are in the closed position.

The literature related to shading louvers covers a large variety of aspects, ranging from the evaluation of thermal performances of façades equipped with this type of devices, ${ }^{13}$ the influence of the geometry of venetian blinds, ${ }^{4}$ the impact of energy savings ${ }^{5} 7$ and even the comfort or discomfort associated with the use of these elements. ${ }^{8} 10$

Typical examples of large glazed façades can be found in airport terminal buildings, where this type of façade has been adopted in many modern airports, as well as in other singular buildings (Figure 1). In order to keep the heat exchange between reasonable boundaries, most of these façades are double-skin façades. Large efforts have been devoted to characterize and control the thermal properties of glazed façades, either single or double skin, ${ }^{11}$ and one of the conclusions is that large glazed façades require, mainly in sunny countries, additional elements for sun protection, in order to reduce the thermal loads due to solar radiation. In airport terminal buildings the shading devices are generally external fixed horizontal louvers with

IDR/UPM, E.T.S.I. Aeronáuticos, Universidad Politécnica de Madrid, E-28040 Madrid, Spain

\section{Corresponding author:}

Gustavo Alonso, IDR/UPM, E.T.S.I. Aeronáuticos, Universidad Politécnica de Madrid, E-28040 Madrid, Spain.

Email: gustavo.alonso@upm.es 


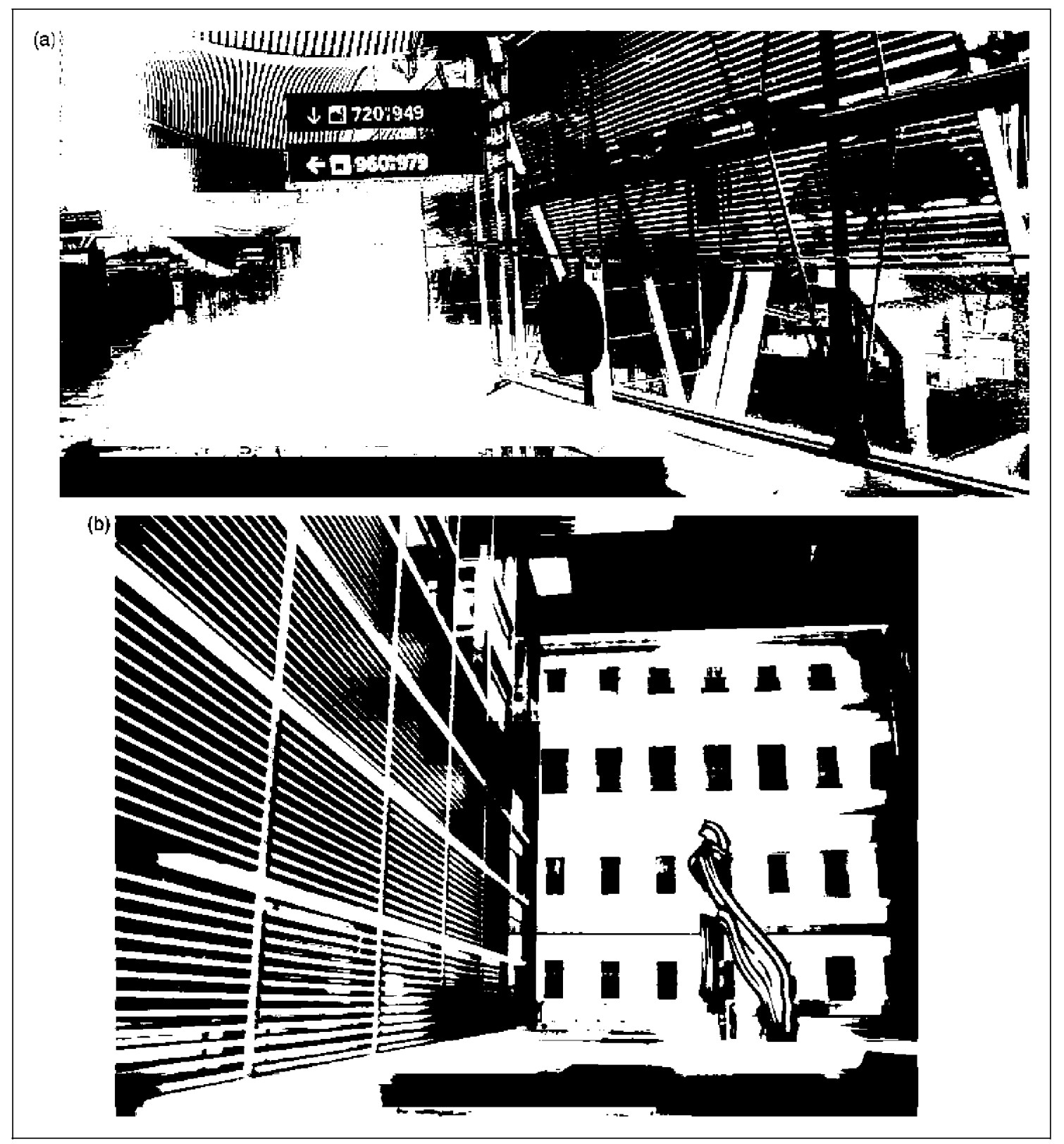

Figure 1. View of a typical glazed façade building with shading devices: Barajas Airport, Terminal 4 (top picture) and Queen Sofia Arts Center (bottom picture).

different slat lengths and tilts (Figure 2), although the shape and the size of such elements can largely vary depending on the application and on the use of the building to be protected. Large slats, either horizontal or vertical, are also used for sun shading in office blocks, and a similar solution is adopted when porous façades are required in order to facilitate natural ventilation. ${ }^{12,13}$ It must be pointed out that when large slats are used, some additional problems can arise, mainly related to wind-induced vibrations. ${ }^{14,15}$

Fixed shading devices are generally used on the external face of glazing since they lower direct radiation from reaching the internal ambient, dissipating the heat to outside. Obviously, external louvers are more efficient than internal fixed shading devices which dissipate the heat to the air gap between the shading device and the glazing. ${ }^{16}$ However, external shading elements are exposed to wind actions, and because of their shapes, they can be aerodynamically unstable. Therefore, an increasingly more important parameter to take into account when designing this type of devices is the action of wind, not only from a static point of view (wind static loads acting on the shading element structure) but also considering the dynamic effects. 


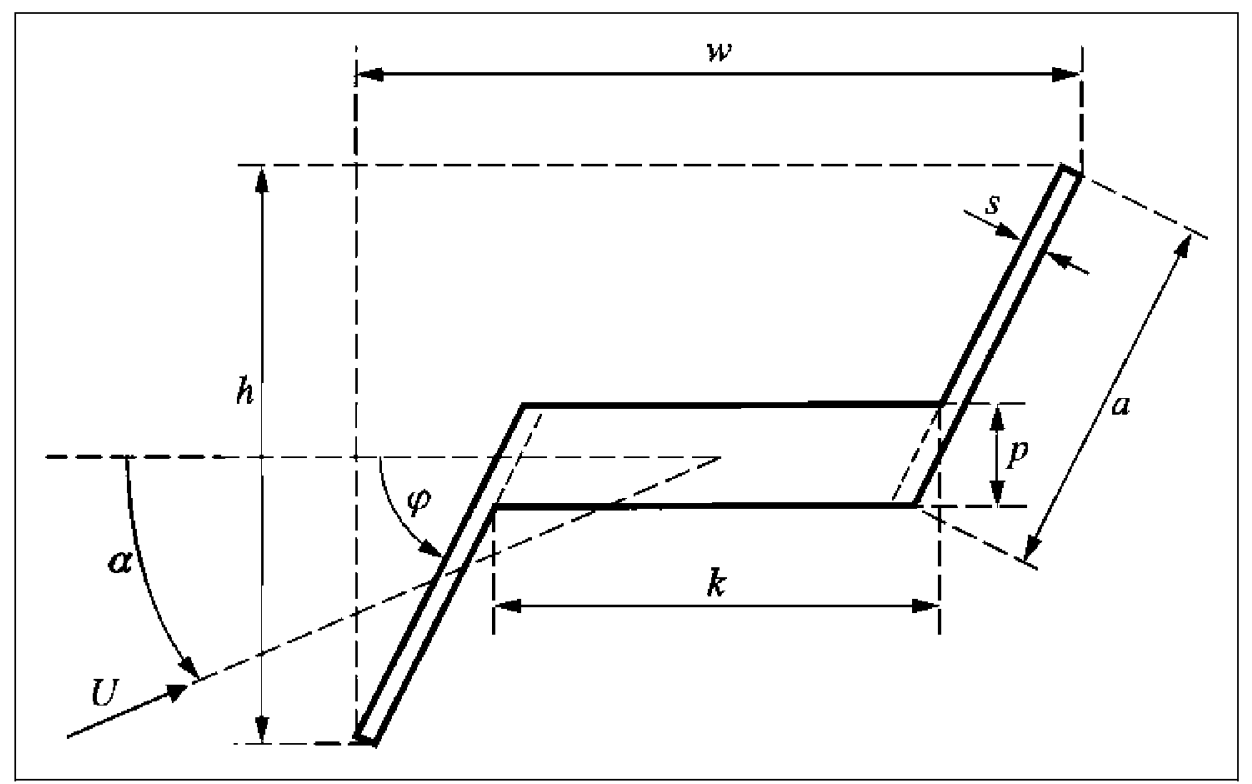

Figure 2. Definition of the parameters involved in the geometry of the Z-shaped louvers.

It is well known that bluff bodies, such as these louvers, are subject in cross-flow to typical aeroelastic phenomena like vortex shedding, translational and torsional galloping, and even flutter. Some of these phenomena can even appear coupled occasionally. Galloping is a typical instability of flexible, lightly damped structures. Under certain conditions these structures may have large amplitude, normal to wind oscillations, at much lower frequencies than those of vortex shedding found in the Kármán vortex street.

The basic principles concerning this phenomenon can be found in Den Hartog. ${ }^{17}$ In the simplest model of galloping (one degree of freedom model) it is assumed that the two-dimensional body, whose mass per unit length is $m$, is elastically mounted on a support with a damping coefficient $\zeta$ and a stiffness $m \omega^{2}$ (where $\omega$ is the angular natural frequency). Within this approximation, if the aerodynamic force (proportional in this case to the vertical wind speed $\mathrm{d} z / \mathrm{d} t$, being $z$ the vertical axis (Figure 3)) is considered as a contribution to the total damping of the system, the total damping coefficient is defined by equation (1)

$$
\zeta_{T}=\zeta+\frac{\rho U b}{4 m \omega}\left(\frac{\mathrm{d} c_{l}}{\mathrm{~d} \alpha}+c_{d}\right)
$$

Therefore, the oscillation will be stable if $\zeta_{T}>0$ and unstable if $\zeta_{T}<0$. As the mechanical damping $\zeta$ is generally positive, instability will only occur if the

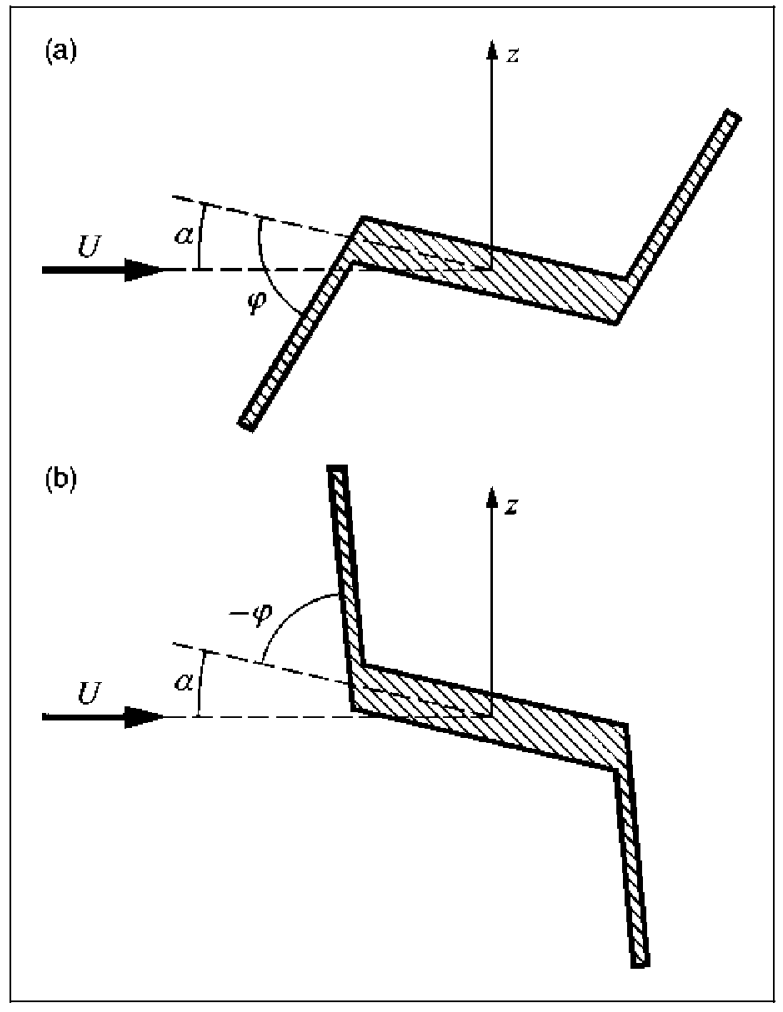

Figure 3. Definition of direct (a) and reverse (b) Z-shaped louvers.

condition for aerodynamic damping $(\mathrm{H})$ is satisfied as defined by equation (2)

$$
H=\frac{\mathrm{d} c_{l}(\alpha)}{\mathrm{d} \alpha}+c_{d}(\alpha)<0
$$


This is an expression known as Den Hartog criterion, which is a necessary condition for galloping instability. The sufficient condition for galloping is $\zeta_{T}<0$, or, according to equation (1)

$$
\frac{\mathrm{d} c_{l}}{\mathrm{~d} \alpha}+c_{d}<-\frac{4 m \zeta \omega}{\rho U b}
$$

Later, in a number of papers, Novak ${ }^{18,19}$ extended the analysis of transverse galloping to the threedimensional case. Other researchers have investigated other interesting phenomena like the influence of turbulence $^{20}$ or the hysteresis ${ }^{21,22}$ in transverse galloping. In the last decades, besides theoretical work and numerical approaches ${ }^{22,23}$ for, large efforts have been devoted to experimentally study the galloping features of many bodies having different cross-sections. Although most of the effort in galloping oscillation research has been concentrated in bodies with square or rectangular cross-sections, prismatic bodies with other cross-sectional shapes have been also considered. ${ }^{24} 31$

Recently, some research on galloping has been carried out at IDR/UPM on the use of large louvers for sun shading in building façades, amongst other applications. A systematic parametric analysis of simple cross-section two-dimensional bodies has been accomplished. The geometries analysed up to now are isosceles triangular cross-sections with the varying parameter being the main vertex angle, $\beta,{ }^{26} 28$ ellipses, ${ }^{30}$ as well as biconvex and rhomboidal crosssections, ${ }^{29}$ the varying parameter in these last cases being the relative thickness of the cross-section, $\tau$. In all cases the unstable regions in the $\beta-\alpha$ plane (isosceles triangles) and in the $\tau-\alpha$ plane (elliptical, biconvex and rhomboidal bodies), where $\alpha$ stands for the wind angle of incidence, were determined.

In this paper the transverse galloping characteristics of $Z$-shaped louvers were analysed through static aerodynamic tests, measuring both overall aerodynamic forces and pressure distributions on the model walls. It must be noted that other aeroelastic phenomena could also be possible in this type of louvers, but they cannot be analysed in a quasi-static manner.

It must be pointed out that galloping has been analysed by using wind tunnel static tests to determine aerodynamic coefficients and then by applying the quasi-static Den Hartog criterion for galloping. This is an indirect way of assessing the galloping instability of a given geometry. The quasi-steady Den Hartog criterion for galloping is a first attempt to clarify if a given body section can gallop or not. This is a necessary condition, but from the dynamic approach there are other factors affecting the galloping behaviour, i.e. those related to the mechanical characteristics of the oscillating body (damping, stiffness), as well as those of the incoming flow (mainly turbulence). However, available published results demonstrate that concerning galloping instabilities, the boundaries between stable and unstable behaviour are almost the same independently of the static or dynamic nature of the tests performed. ${ }^{26}$

\section{Experimental setup}

The louvers, as sketched in Figure 2, consist of a thick central body (web) with two thin plates attached to its extremes (wings). The geometry of the Z-shaped louvers is defined by the length of the central web, $k$, and the angle $\varphi$; other geometrical parameters are the thickness of this central body, $p$, as well as the length and the thickness of the wings, $a$ and $s$, respectively. Then, the width and the height of the slat are as defined by equation (4)

$$
\left.\begin{array}{l}
w=(2 a-p) \cos \varphi+2 s \sin \varphi+k \\
h=2 a \sin \varphi+2 s \cos \varphi-p
\end{array}\right\}
$$

From these two equations the chord of the $Z$-shaped louver is $c^{2}=w^{2}+h^{2}$. Therefore, once the values of five of the six parameters involved are fixed (say $c, p, s, k$ and $\varphi$ ), the value of the remaining one results (in this case the length of the wings, $a$ ). In all cases where overall aerodynamic forces were measured the chord of the slats was $c=0.1 \mathrm{~m}$ and the values of the parameters $s, p$ and $k$ being $s=0.012 c, p=0.1 c$ and $k=0.1(n+1) c$, where $n$ stands for a natural number. Two different families of louvers, identified by the angle $\varphi$, and for each one of them different geometries were considered, namely $\varphi=90^{\circ}$, with $n=1,2, \ldots, 7$, and $\varphi=45^{\circ}$, with $n=1,2, \ldots, 7$. Note that each model defines two different testing configurations, depending, for instance, on the relative position of the forward wing at zero angle of attack. According to Figure 3 the forward wing can be pointing down or pointing up. The pointing-up positions are identified in the following as $\varphi=-90^{\circ}$ and $\varphi=-45^{\circ}$ (such configurations are called in the following as reverse louvers). However, these pointing-up positions were not tested because their aerodynamic coefficient can be easily expressed in terms of the corresponding pointing-down ones (direct louvers), once both the periodicity of the coefficients, $\quad c_{f}(\varphi, \pi+\alpha)=c_{h}(\varphi, \alpha), \quad c_{d}(\varphi, \pi+\alpha)=c_{d}(\varphi, \alpha)$, and the geometrical symmetries are taken into account. Then

$$
\left.\begin{array}{l}
c_{l}(-\varphi, \beta)=-c_{l}(\varphi, \pi-\alpha) \\
c_{d}(-\varphi, \beta)=c_{d}(\varphi, \pi-\alpha)
\end{array}\right\}
$$

The whole set of tested louver shapes is shown in Figure 4. 


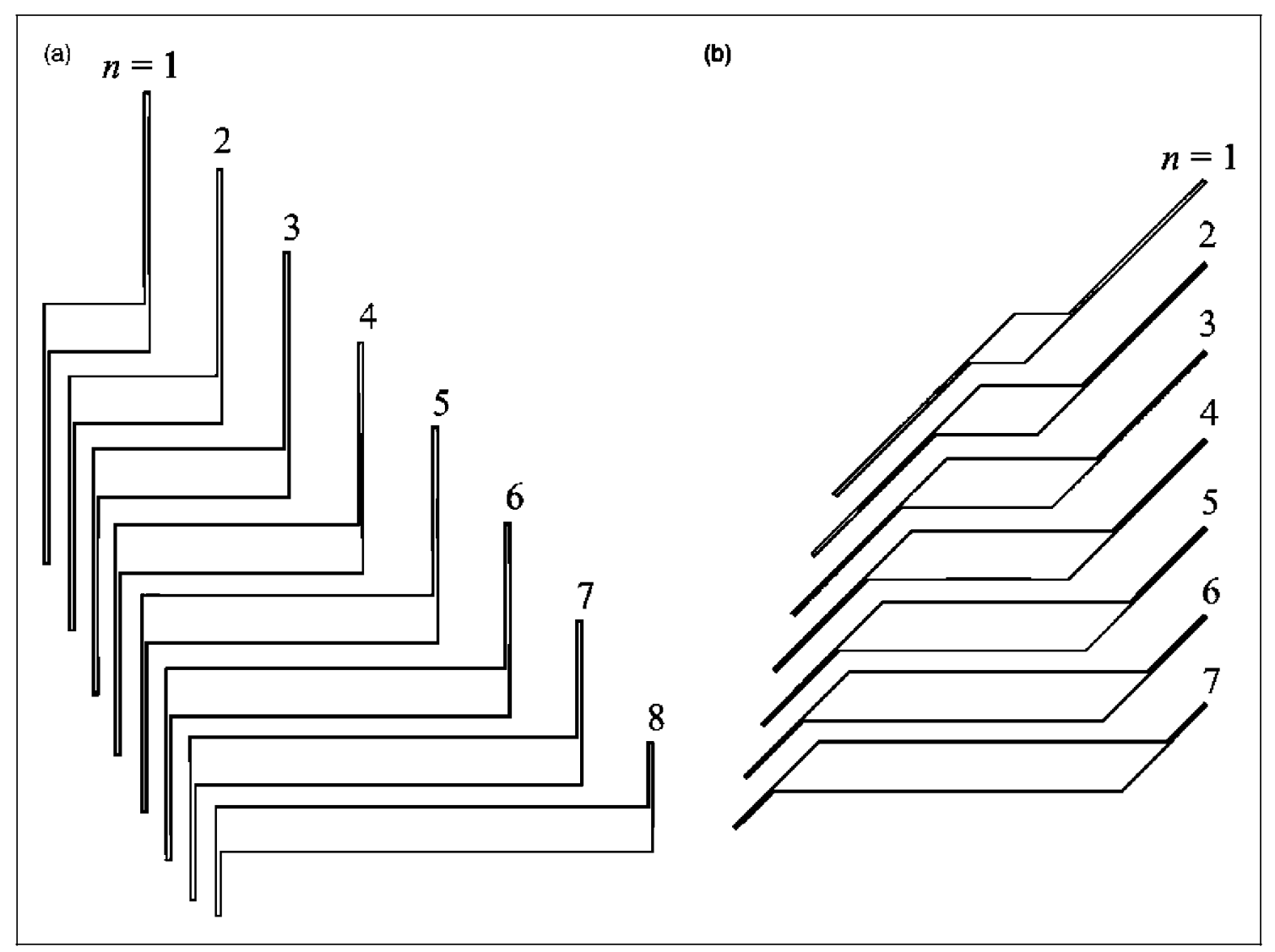

Figure 4. Sketches of the tested Z-shaped louvers: $\varphi=90^{\circ}$

(a) and $\varphi=45^{\circ}$ (b).

\section{Aerodynamic coefficients measurement}

Aerodynamic force coefficients, lift and aerodynamic drag, were measured in an open circuit twodimensional wind tunnel, using rigidly mounted configurations. Wind tunnel test chamber is $0.15 \mathrm{~m}$ width, $0.90 \mathrm{~m}$ high and $1.20 \mathrm{~m}$ long. Aerodynamic loads were measured with a six-component strain-gauge balance (ATI, model Gamma SI-130-10) already used in other galloping tests. ${ }^{26}{ }^{30}$ The balance was mounted on a fixed reference frame in such a way that one of the balance axes becomes aligned with the upstream direction. The balance supports a rotating platform to which the model was fixed through an appropriated screw. The rotating platform allows setting the model angle of attack with $\pm 1^{\circ}$ accuracy. The balance has a maximum measurement uncertainty of $1.25 \%$. A sketch of the experimental setup is shown in Figure 5, where the main elements are identified.

Wind velocity profile at the model test section was uniform within $\pm 1 \%$ and the turbulence intensity being around $4 \%$. The maximum wind velocity of the stream at the test section of the wind tunnel was $25 \mathrm{~m} / \mathrm{s}$, so that the maximum value of the Reynolds number based on the model chord, $c=0.1 \mathrm{~m}$, as already said, was

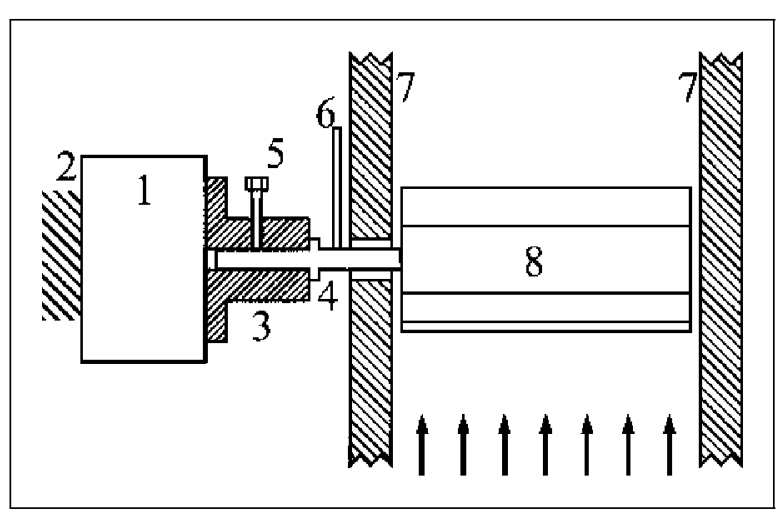

Figure 5. Sketch of the experimental setup, with indication of the main elements: 1: Strain-gauge balance, 2: reference frame; 3 : housing of the rotating axis; 4 : rotating axis; 5: screw to fix the position of the rotating axis; 6 : needle to fix the angular position of the axis; 7 : wind tunnel walls; 8: test model.

$\operatorname{Re}=1.7 \times 10^{5}$. The span of all the models was $0.14 \mathrm{~m}$, allowing thus for a gap of $1 \mathrm{~mm}$ between the end of the model not supported by the balance and the tunnel wall. No blockage corrections of the measured results have been considered, as even in the worst case the 
areas of the testing models were smaller than $12 \%$ of the wind tunnel cross-section. The flow dynamic pressure inside the wind tunnel test chamber was measured with an Air Flow 048 Pitot tube connected to a Schaewitz Lucas P-3061-2WD pressure transducer.

During the tests no special provisions were undertaken to avoid air flow through the gap between the model and the wind tunnel test section walls. This gap was not included in the correction of the measured results, and in any case the effect was assumed to be small. In order to verify that this assumption was correct, the characterization procedure of all twodimensional wind tunnels existing at IDR/UPM includes some previous measurements by using a symmetric airfoil model equipped with pressure taps. The model is a NACA $0012^{32}$ equipped with 57 pressure taps distributed in three sections, located at $y / d=1 / 9$, $1 / 4$ and $1 / 2$, where $y$ is the distance from one of the model tips and $d$ is the model span and in this case $d=19.5 \mathrm{~cm}$. At each measuring section there are nine pressure taps on the upper surface, another nine pressure taps on the lower surface, plus one additional pressure tap at the leading edge. In these previous tests, pressure distributions were measured, and recorded, at $125 \mathrm{~Hz}$ sampling rate during $10 \mathrm{~s}$. This test was used to evaluate the two-dimensional character of the flow acting on the aerofoil, as it was demonstrated from the comparison of measured pressure distributions at different span locations, where no significant differences were found. ${ }^{31,33}$

Once a selected model was fixed to the rotating platform, angles of attack were varied from $\alpha=0^{\circ}$ to $\alpha=180^{\circ}$ at $2^{\circ}$ steps, and at each step the six outputs coming from the strain-gauge balance were stored in a $\mathrm{PC}$, as well as the dynamic pressure inside the test chamber. The averaging period used for the mean force coefficients measurements was $10 \mathrm{~s}$ at a sampling frequency of $20 \mathrm{~Hz}$. Since tests were performed in smooth flow, these selected values were large enough to assure that mean force coefficients are independent of both sampling rate and measuring time.

The lift and drag coefficients were calculated from the appropriate outputs, and from these the function $H(\varphi, \alpha, n)=\mathrm{d} c_{l} / \mathrm{d} \alpha+c_{d}$ was determined.

It must be pointed out that in the wind tunnel tests there was not any façade behind the louver, and therefore there were no restrictions to the air flow. This fact makes test conditions more critical than the actual ones, as explained in Appendix 1.

\section{Pressure distribution measurement}

Again on a rigidly mounted configuration, a model was instrumented with pressure taps in order to determine the pressure distribution on the model walls. A larger

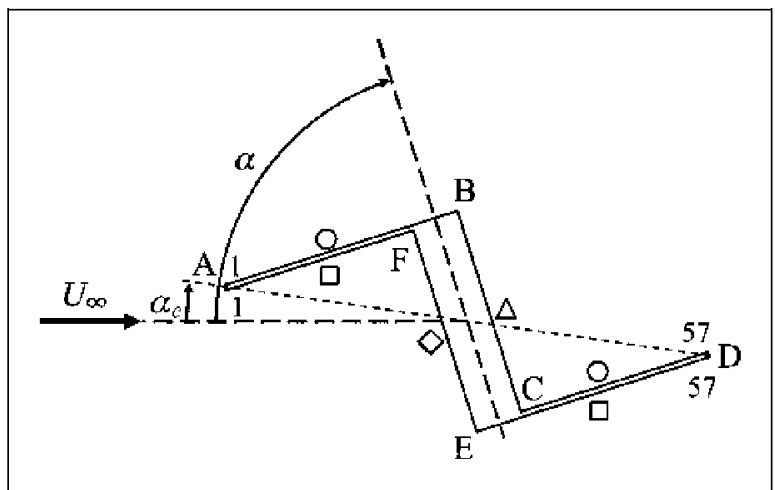

Figure 6. Sketch of the Z-shaped louver $\left(\varphi=90^{\circ}, n=4\right)$ used in pressure measurements with indication of the nomenclature used to identify experimental results in Figure 7. Circles represent taps in faces $A B(1-22)$ and $C D$ (40-57). Triangles represent taps in face BC (23-39). Squares represent taps in faces AF (1-22) and ED (40-57). Rhombi represent taps in face FE (23-39).

model than the ones used in the aerodynamic forces measurements has been used, to allow an easier installation of pressure taps (the dimensions of the pressure model are defined below). This model was tested by using smooth flow in the wind tunnel A9 of IDR/UPM whose test chamber is $1.8 \mathrm{~m}$ high and $1.5 \mathrm{~m}$ wide.

The profile chosen was one corresponding to a configuration with $\varphi=90^{\circ}$ and lengths of the central web and the side wings, $k=180 \mathrm{~mm}$ and $a=225 \mathrm{~mm}$, respectively; thicknesses, $p=45 \mathrm{~mm}$ for the central body, and $s=5.4 \mathrm{~mm}$ for the wings. In order to measure the wall static pressure, a total of 114 pressure taps uniformly distributed along the prism were drilled with a separation of $10 \mathrm{~mm}$ between taps: 57 taps in what we could call the upper side of the model (taps from 1 to 22 in the $\mathrm{AB}$ face, from 23 to 39 in the $\mathrm{BC}$ face, from 40 to 57 in the $\mathrm{CD}$ face), and another 57 taps in the lower side of the model (taps from 1 to 22 in the AF face, from 23 to 39 in the FE face, from 40 to 57 in the ED face). A sketch with the distribution of the taps is shown in Figure 6, whereas a picture of the louver under consideration showing the internal pressure piping is shown in Figure 7. Two pressure scanners from Scanivalve Corp. (model 48J7-1), each one equipped with a Druck PDCR22 differential pressure transducer were attached therein. The pressure signal (sampling frequency of $20 \mathrm{~Hz}$ ) was sent to a PC. A total of 250 pressure signals at a given location were time averaged to obtain the local pressure coefficient. Also in pressure measurements tests, since tests were performed in low turbulent flow, the selected values for sampling rate and measuring time were large enough to assure that mean pressure coefficients were independent of flow conditions. 


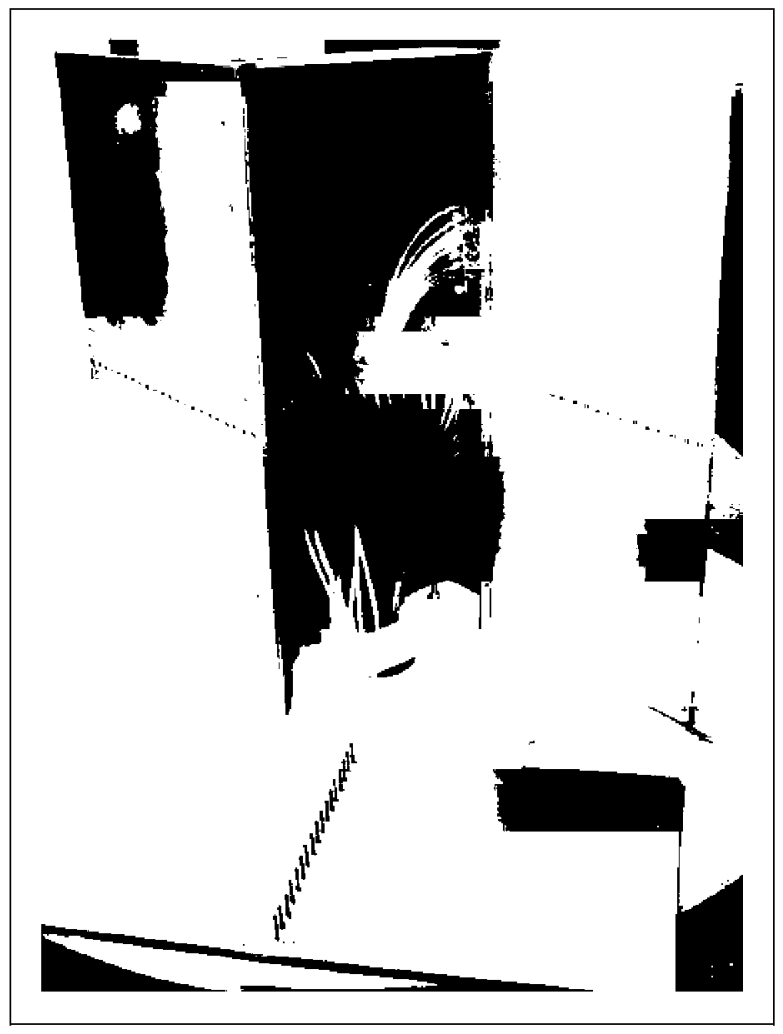

Figure 7. Picture of the Z-shaped louver $\left(\varphi=90^{\circ}, n=4\right)$ used in pressure measurements, showing the internal piping used to connect pressure taps with pressure transducers.

Pressure taps were made out of brass tube with a $1 \mathrm{~mm}$ internal diameter. The tube was mounted such as one of its ends was carefully positioned flush with the surface where pressure was to be measured, and the opposite end was connected through a flexible plastic tube to the measurement equipment which was placed outside of the wind tunnel test section. The model was mounted on an ESP100/RV80PP rotating platform from Newport. All the experimental sequences, the different values of the angle of attack, pressure measurements and data saving, were controlled by a PC. The pressure distributions were recorded at $200 \mathrm{~Hz}$ sampling rate during $30 \mathrm{~s}$.

The flow stagnation pressure, $p_{0}$, and the static pressure in the test section, $p_{\infty}$, were measured by an Air Flow 048 Pitot tube located at the ceiling of the test chamber, connected to a Druck LPM5480 pressure transducer. Pressure coefficients were defined as usual: $c_{p j}=\left(p_{j}-p_{\infty}\right) /\left(p_{0}-p_{\infty}\right)$, where $p_{j}$ was the static pressure measured at $j$ th pressure tap. From pressure coefficient distribution the normal force coefficient to each one of the flat surfaces of the body was obtained, thus the global force coefficient on the Z-shaped louver resulted.
With this experimental setup pressures have been measured on the prism walls for angles of incidence $\alpha$ ranging from $0^{\circ}$ to $165^{\circ}$, in $15^{\circ}$ steps.

\section{Experimental results}

\section{Isolated louver}

Experimental results are shown in Figure $8\left(\varphi=90^{\circ}\right)$ and in Figure $9\left(\varphi=45^{\circ}\right)$. In each one of the plots included in these figures the variation with the angle of attack $\alpha$ of the louver lift coefficient, $c(\varphi, \alpha)$; the drag coefficient, $c_{d}(\varphi, \alpha)$ and the function $H(\varphi, \alpha)$ have been represented for the corresponding value of the parameter $n$ (the results shown in these figures correspond to a Reynolds number $\mathrm{Re} \cong 10^{5}$ ).

According to Figure $8\left(\varphi=90^{\circ}\right)$, in the case $n=1$ the slat behaves almost like a flat plate normal to the flow at $\alpha=0^{\circ}$, the drag coefficient is high and the lift coefficient negative. Let us introduce now another angle of attack $\alpha_{c}$ taking as a reference the louver chord, then $\alpha_{c}=\alpha+\operatorname{atan}(h / w)-\pi / 2$, where $\alpha, h$ and $w$ are defined in Figure $2\left(\operatorname{atan}(h / w) \approx 7^{\circ}\right.$ if $\left.n=1\right)$. The minimum value of the lift coefficient is reached at $\alpha \cong 28^{\circ}$ $\left(\alpha_{c} \cong-55^{\circ}\right.$, close enough to the value where a flat plate reaches its minimum lift coefficient, i.e. $\left.\alpha \cong-45^{\circ}\right)$. From this angle of attack the lift starts to grow, and it becomes positive at $\alpha \cong 70^{\circ}\left(\alpha_{c} \cong-13^{\circ}\right)$, where the drag coefficient reaches its minimum value. Beyond this angle of attack both the lift coefficient and the drag coefficient grow, until the lift coefficient becomes maximum at $\alpha \cong 90^{\circ}\left(\alpha_{c} \cong 7^{\circ}\right)$. For $\alpha>90^{\circ}$ the behaviour of both $c_{l}$ and $c_{d}$ resembles that of a flat plate: $c_{l}$ first decreases and then increases until a second maximum is reached at $\alpha \cong 125^{\circ}\left(\alpha_{c} \cong 42^{\circ}\right)$, as one could expect. Note that the $n=1$ configuration is potentially unstable only between $\alpha \cong 90^{\circ}$ and $\alpha \cong 100^{\circ}$, where the lift slope is slightly negative and the drag coefficient small enough.

Obviously experimental results continuously change as the geometrical parameter $n$ grows. For $n=2$ the maximum of the lift curve placed close to $\alpha=90^{\circ}$ accentuates, and the lift slope curve beyond this maximum becomes more negative. The minimum aerodynamic drag increases by a small amount, but the function $H(\varphi, \alpha)=\mathrm{d} c_{l} / \mathrm{d} \alpha+c_{d}$ becomes more negative. Note that in this case, $n=2$, the maximum drag coefficient is reached at $\alpha \cong 166^{\circ}\left(\alpha_{c} \cong 89^{\circ}\right.$, because now $\operatorname{atan}(h / w)$ $\approx 13^{\circ}$ ), that is when the louver chord is practically perpendicular to the incident flow.

As the parameter $n$ increases the maximum of the drag coefficient curve moves towards smaller values of the angle of attack, as well as the maximum of the lift coefficient curve does. Note that the second maximum on the $c_{l}$ curve decreases as $n$ grows until it practically 


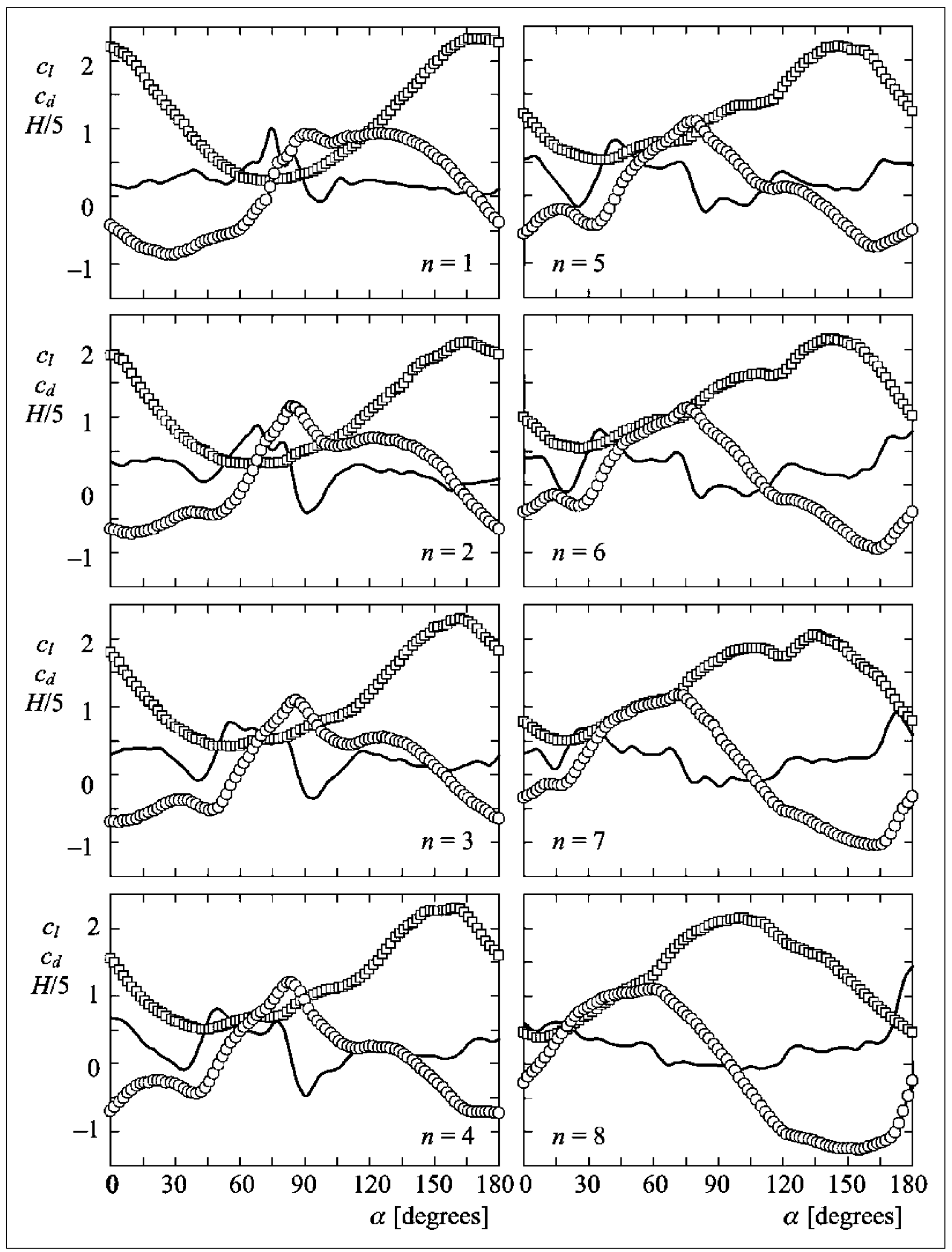

Figure 8. Variation with the angle of attack $\alpha$ of the lift coefficient $c_{l}$ (circles), the aerodynamic drag $c_{d}$ (squares) and the function $H=\mathrm{d} c_{l} / \mathrm{d} \alpha+c_{d}$ (thick line), corresponding to Z-shaped cross-section bodies with $\varphi=90^{\circ}$. The value of the shape parameter $n$ is indicated in the insets. Note that $H / 5$ instead of $H$ is depicted in the plots. 


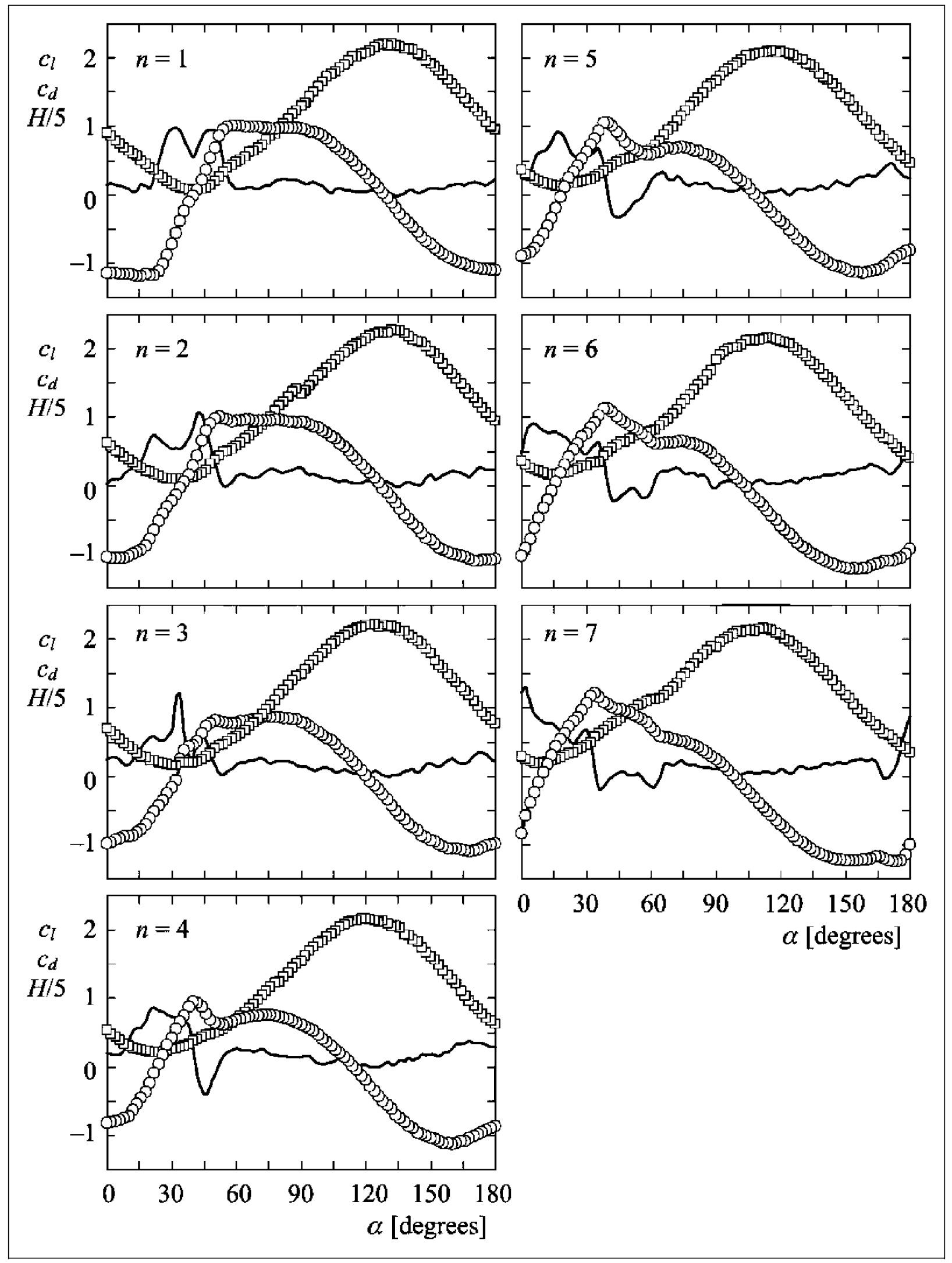

Figure 9. Variation with the angle of attack $\alpha$ of the lift coefficient $c_{l}$ (circles), the aerodynamic drag $c_{d}$ (squares) and the function $H=\mathrm{d} c_{l} / \mathrm{d} \alpha+c_{d}$ (thick line), corresponding to Z-shaped cross-section bodies with $\varphi=45^{\circ}$. The value of the shape parameter $n$ is indicated in the insets. Note that $H / 5$ instead of $H$ is depicted in the plots. 


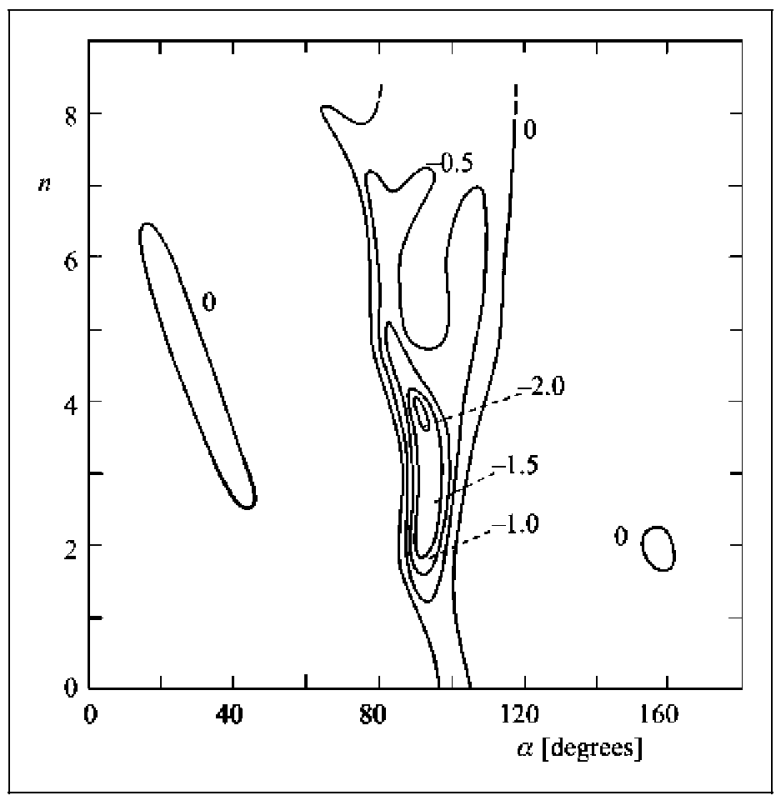

Figure 10. Stability diagram in the angle of attackgeometry parameter plane $(\alpha, n)$ of Z-shaped louvers with $\varphi=90^{\circ}$. Results are based on static test results. Numbers on the curves indicate the value of the function $H=\mathrm{d} c_{l} / \mathrm{d} \alpha+c_{d}$.

disappears at $n=5$ (Figure 8). For even larger values of $n$ there is a wide range of angles of attack around $\alpha=90^{\circ}$ where the lift slope curve is negative, thus increasing the range on angles of attack where the function $H(\varphi, \alpha)$ can be negative (depending on the value of the drag coefficient).

All these instability features concerning $\varphi=90^{\circ}$ Z-shaped louvers are summarized in Figure 10, where the different stability regions have been plotted in the $n-\alpha$ plane. In this plot the curves corresponding to several values of the function $H(\varphi, \alpha, n)$ have been represented. Note that there is an instability region close to $\alpha=90^{\circ}$ (where the upstream flow is almost parallel to the profile wings), which becomes wider as the length of these wings decreases and finally practically disappears at $n=8$. However, it must be stressed that the louver configuration becomes a rectangular crosssection cylinder at $n=9.7$ (then is $a=1$ ) with a very small aspect ratio at $\alpha=90^{\circ}$, which is unstable. Because of the low relative thickness such a rectangular louver behaves almost a flat plate, so that it gallops as the flat plate represented by the $n=0$ configuration, but with the angle of attack shifted $-90^{\circ}$.

There is a second narrow instability region which only appears for intermediate values of $n$. This unstable region is close to $\alpha=40^{\circ}$ for $n=3$ and it moves to $\alpha=20^{\circ}$ for $n=6$. A noticeable feature of this narrow unstable region is that the angle of attack of the louver chord, $\alpha_{c}=\alpha+\operatorname{atan}(h / w)-\pi / 2$, is practically constant, $\alpha_{c} \approx 30^{\circ}$, irrespective of the value of $n$.

As already said, the results shown in Figure 10 are also applicable to the reverse louvers $\left(\varphi=-90^{\circ}\right)$. In effect, according to expressions (5), since $\beta=\pi-\alpha$, the reverse louvers behave exactly equal to the tested ones, but the unstable regions now appear at complementary angles $\beta=\pi-\alpha$.

Galloping instabilities are very much related to the flow morphology around the body, and specifically to the flow separation and reattachment mechanism. Like in other sharp-edged bodies, ${ }^{26}{ }^{29}$ in Z-shaped profiles depending on the angle of attack, $\alpha$, the boundary layer separates at the corresponding windward corner, and reattaches further in one of the walls of the body, forming a recirculation bubble. With the variation of $\alpha$ the size of that recirculation bubble increases. At a certain value of $\alpha$ the recirculation bubble has grown so much that it reaches the trailing edge of the body. From then on reattachment is no longer possible and the slope of the lift coefficient becomes negative leading to a potential galloping instability therefore.

The galloping behaviour of $Z$-shaped louvers can be better understood by examining the pressure distribution on the model walls as a function of the angle of attack, which gives us an indication of the flow morphology around the body as that angle varies. In Figure 11 the results corresponding to the case $\varphi=90^{\circ}, n=4$ have been represented. When the angle of incidence, $\alpha$, is zero the chord angle of attack, $\alpha_{c}$, is extremely negative $\left(\alpha_{c} \approx \alpha-65^{\circ}\right.$ is the angle of attack taking the louver chord, line AD, as reference, Figure 6), so that the lift coefficient is negative and the drag coefficient is large. Looking to the flow morphology at small angles of incidence, since the unperturbed flow is normal to the faces $\mathrm{AB}$ and $\mathrm{CD}\left(\right.$ at $\alpha=0^{\circ}$ ) there must be a stagnation point on the face $\mathrm{AB}$. The boundary layer starting at such forward stagnation point that flows towards the edge A separates at this point, whereas that flowing towards the edge B separates at B. Depending on the length of the central body (the value of $n$ ) the boundary layer separated at $\mathrm{B}$ could reattach on the face $\mathrm{BC}$, although this would be only possible when the value of $n$ is large enough, otherwise (because there must be an stagnation point at $\mathrm{C}$, and this implies large adverse pressure gradients on the face $\mathrm{BC}$ ), a recirculation bubble is formed on the corner BCD. Experimental results show that at $\alpha=0^{\circ}$ no reattachment occurs, so that pressure coefficients on both faces, $\mathrm{BC}$ and $\mathrm{CD}$, have almost the same values. Note that the flow accelerates close to edges A and D. The pressure coefficients at these points become more negative, and a wide wake is formed downstream of the louver. The pressure coefficients are almost uniform and negative at faces $\mathrm{AF}, \mathrm{FE}$ and $\mathrm{ED}$. 


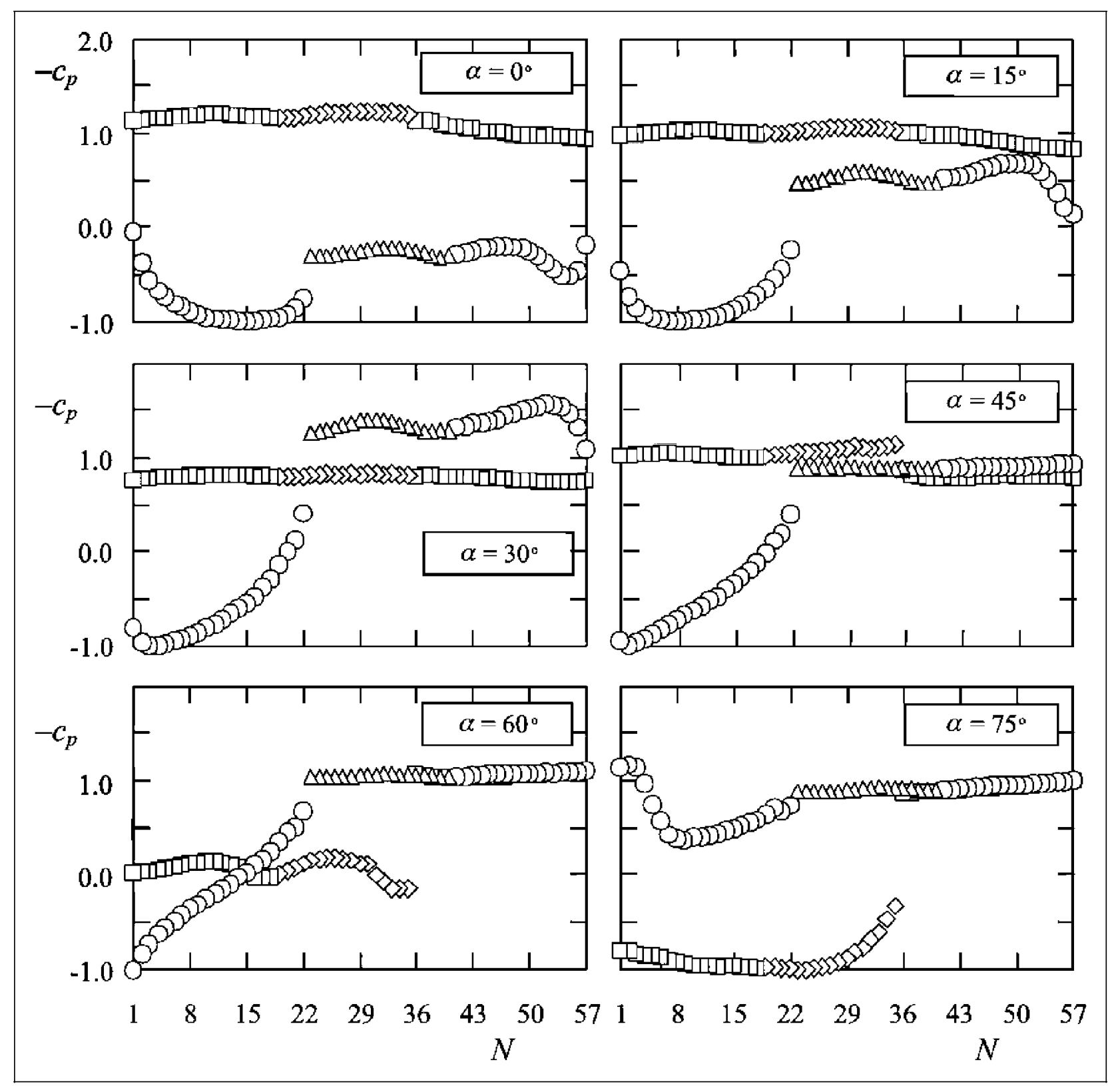

Figure 11. Pressure distribution (pressure coefficient, $c_{p}$ versus tap number, $N$ ) on a Z-shaped louver $\left(\varphi=90^{\circ}\right.$, $n=4)$ at different angles of attack $\left(0^{\circ} \leq \alpha \leq 75^{\circ}\right)$. Following nomenclature in Figure 9, circles represent taps in faces $A B(1-22)$ and $C D(40-57)$; triangles represent taps in face $B C$ (23-39); squares represent taps in faces $A F(1-22)$ and ED (40-57); rhombi represent taps in face FE (23-39).

This is no longer valid when $\alpha=0^{\circ}$, when windward surfaces $\mathrm{AB}$ and $\mathrm{CD}$ are perpendicular to the wind flow whereas surface $B C$ is aligned with the unperturbed flow velocity. In this case, as one would expect, the flow at the windward surfaces is stagnated, with a clear stagnation point at surface $\mathrm{AB}$.

Note also that since pressure forces are normal to the solid surfaces, in the case of Z-shaped louvers with $\varphi=90^{\circ}$ pressure distributions give an accurate idea on the forces acting on the louver. The mean aerodynamic force normal to the two thin plates (wings) is

$$
\begin{aligned}
f_{w}= & \frac{1}{2} \rho U^{2} \\
& \times\left(\sum_{\mathrm{AB}} c_{p, j} \delta_{j}-\sum_{\mathrm{AF}} c_{p, j} \delta_{j}+\sum_{\mathrm{CD}} c_{p, j} \delta_{j}-\sum_{\mathrm{ED}} c_{p, j} \delta_{j}\right)
\end{aligned}
$$




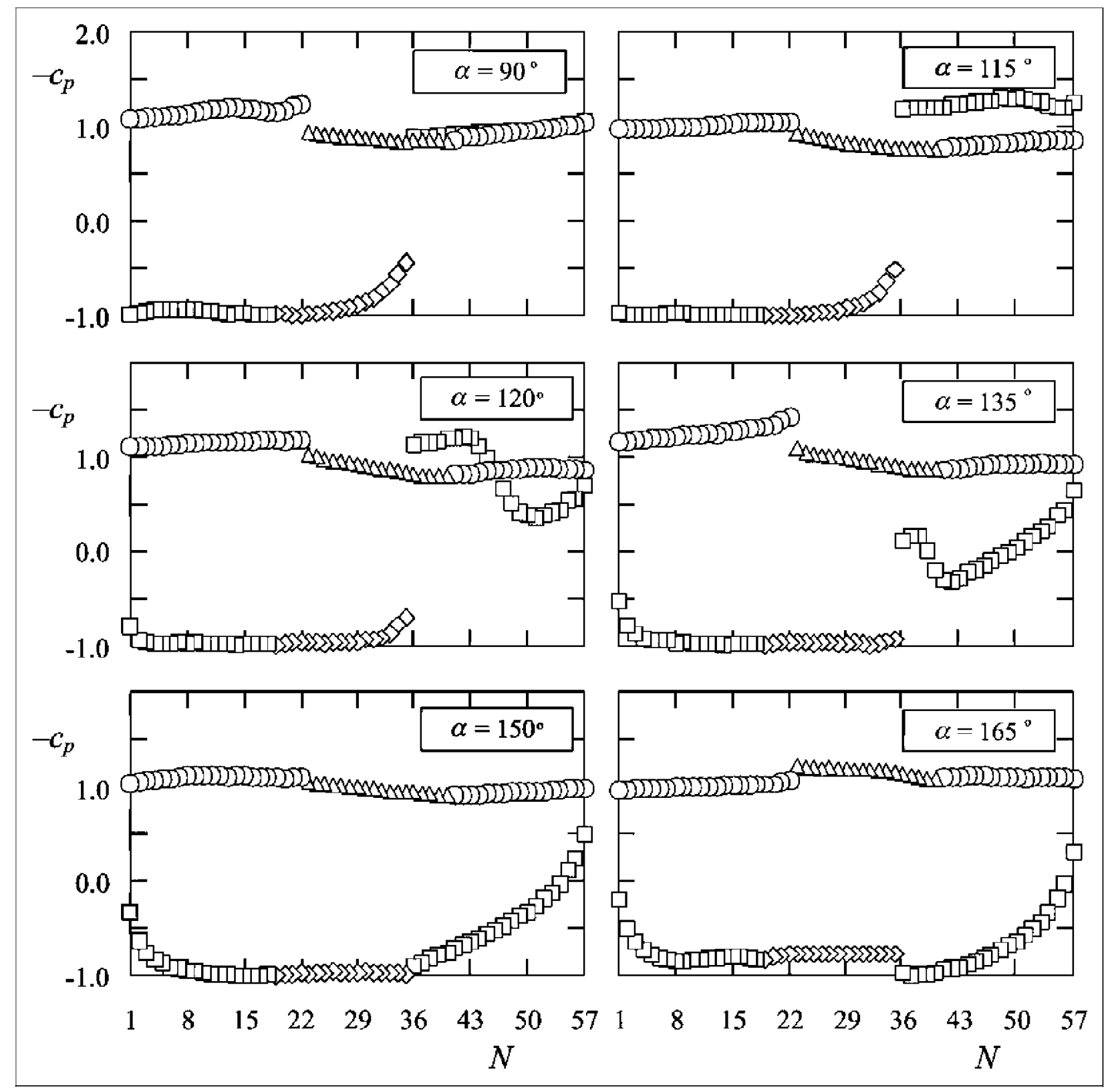

Figure 11. Continued.

where $\delta_{j}$ are the length of influence corresponding to each pressure tap (note that $f_{w}$ is a force per unit width). According to equation (6) this force is positive when is directed from B to C. On the other hand, the aerodynamic force normal to the web (central body) is

$$
f_{b}=\frac{1}{2} \rho U^{2}\left(\sum_{\mathrm{FE}} c_{p, j} \delta_{j}-\sum_{\mathrm{BC}} c_{p, j} \delta_{j}\right)
$$

which is positive when is directed from A to B.

According to these definitions the plots of the experimental results give a quick indication on the forces acting on the louver: the area between squares and circles gives the force normal to the wing, positive when the circles are over the squares. The area between rhombi and triangles gives the aerodynamic force normal to the central body, positive when the triangles are over the rhombi. Therefore, the lift and drag forces are

$$
\left.\begin{array}{l}
l=f_{w} \sin \alpha+f_{b} \cos \alpha \\
d=-f_{w} \cos \alpha+f_{b} \sin \alpha
\end{array}\right\}
$$

so that when $\alpha=0^{\circ} l=f_{b}$ and $d=-f_{w}$.

As the angle of attack increases the stagnation point of face $A B$ moves towards edge $A$, the boundary 
layer being separated in all other faces. In this situation the main contribution to aerodynamic forces is due to faces $\mathrm{AB}$ and $\mathrm{AF}$ (see the plot corresponding to $\alpha=45^{\circ}$, Figure 11). At $\alpha \cong 60^{\circ}$ (that means $\alpha_{c} \cong 0^{\circ}$ ) the forward stagnation point reaches the edge $A$, such stagnation point jumping to face $\mathrm{AF}$ when $\alpha$ increases. This last pressure configuration is clearly depicted in the plot corresponding to $\alpha=75^{\circ}$, now there is a severe suction peak on face $A B$ close to edge $A$, whereas the flow is almost stagnated in the corner AFE (see Figure 6). Such situation becomes even stressed at $\alpha=75^{\circ}$, now the lift force is practically due to the forward wing (now is $l=f_{w}$ and $d=f_{b}$, both forces being positive). The reason for such a behaviour is that the drag force due to wing $A B$ decreases both because the pressure force (the area between experimental curves) decreases and the angle of attack increases. The contributions of the central body and the rear wing $\mathrm{CD}$ are almost negligible at $\alpha=45^{\circ}$, Figure 11 .

From $\alpha \cong 75^{\circ}$ to $\alpha \cong 165^{\circ}$ the wing $\mathrm{AB}-\mathrm{AF}$ produces a positive normal force and so does the central body. However, the contribution to the lift force due to the central body becomes negative for $\alpha>90^{\circ}$, whereas the lift due to the forward wing $\mathrm{AB}-\mathrm{AF}$ decreases beyond this angle. This explains why the total lift coefficient decreases and the drag coefficient grows.

Finally, note that at $\alpha=165^{\circ}$ the measured pressure distribution approaches the one measured at $\alpha=0^{\circ}$. Obviously pressure distributions measured at $\alpha=0^{\circ}$ and $\alpha=180^{\circ}$ must be the same, once the existing symmetries are considered.

In the case $\varphi=45^{\circ}$ the louvers are more streamlined than in the $\varphi=90^{\circ}$ case, although they are also wedged bodies, so that the variation with the angle of attack of the force coefficients is smoother than in the previous case. From the curves of the variation with the angle of attack of the function $H(\varphi, \alpha)$ shown in Figure 9, the stability map corresponding to the $\varphi=45^{\circ}$ louvers is presented in Figure 12. Also in this plot the curves corresponding to several values of the function $H(\varphi, \alpha, n)$ have been represented. Note that the louvers with $\varphi=45^{\circ}$ are less prone to gallop than the ones with $\varphi=90^{\circ}$. The instability region reduces to a small interval of angles of attack around $\alpha \approx 45^{\circ}$ and only for values of the geometrical parameter $n>3$, with the exception of $n=7$ where a very small instability appears at $\alpha \approx 170^{\circ}$.

\section{Tandem configuration}

Since louvers are integrated in arrays, some preliminary tests have been performed aiming at clarifying the influence of the position of the louver within the array

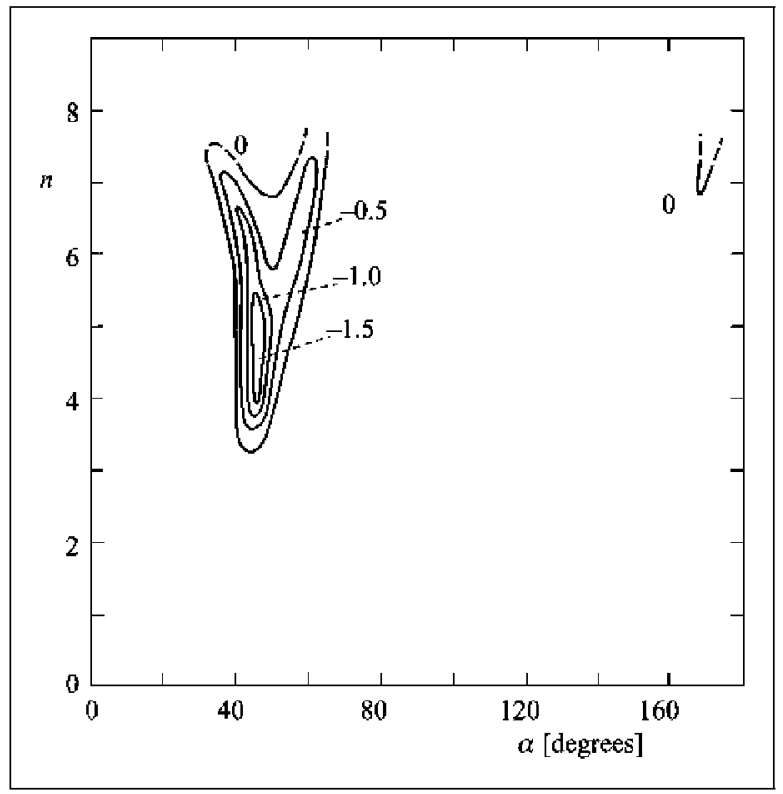

Figure 12. Stability diagram in the angle of attackgeometry parameter plane $(\alpha, n)$ of Z-shaped louvers with $\varphi=45^{\circ}$. Results are based on static test results. Numbers on the curves indicate the value of the function $H=\mathrm{d} c_{l} / \mathrm{d} \alpha+c_{d}$.

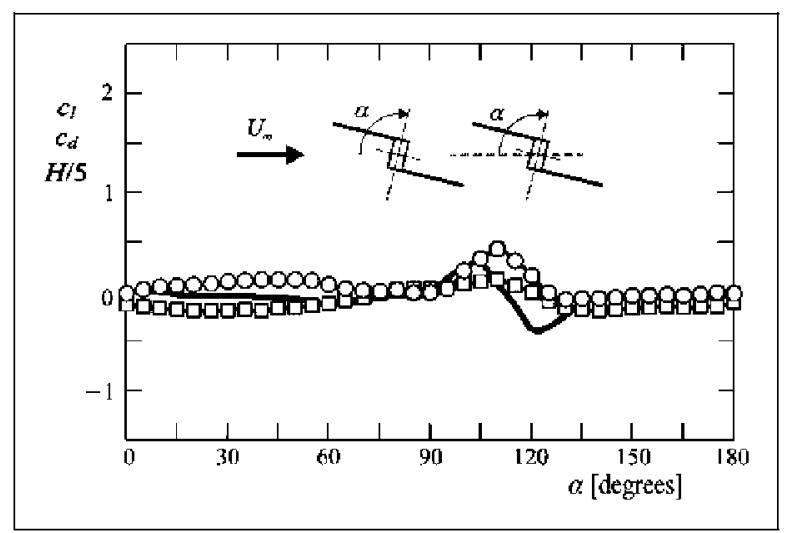

Figure 13. Sketch of two Z-shaped louvers arranged in tandem $\left(\varphi=90^{\circ}, n=2\right)$; variation with the angle of attack $\alpha$ of the lift coefficient $c_{l}$ (circles), the aerodynamic drag $c_{d}$ (squares) and the function $H=\mathrm{d} c_{l} / \mathrm{d} \alpha+c_{d}$ (thick line), corresponding to the leeward louver.

on the galloping behaviour. The tested configuration consists of two Z-shaped louvers $\left(\varphi=90^{\circ}, n=2\right)$ arranged in tandem (Figure 13). This configuration can be found in canopies. In this case only the leeward louver is connected to the balance, although both louvers rotate in phase. The distance between louver axes has been selected to allow a gap of $1 \mathrm{~mm}$ between them, such a minimum gap is reached at $\alpha \cong 79^{\circ}$. Aerodynamic coefficients as well as the function $H$ defined in expression (2) measured in the leeward 
louver are also depicted in Figure 13. As it can be observed, since leeward louver is always in the wake of the windward one, aerodynamic coefficients are small when compared with those corresponding to an isolated louver. Experimental results show that the leeward louver is only prone to gallop in a narrow interval of angles of attack close to $\alpha=120^{\circ}$. At this angle of attack the wake of the windward louver is thin enough to allow the windward louver to be partly outside of the windward louver wake. Outside such a critical interval of angles of attack the leeward louver is totally immersed in the wake of the former. Obviously the same behaviour occurs in other Z-shaped louver in tandem arrangement. Note that the results shown in Figure 13 refer to classical galloping, not to wake galloping, which depends on the variation of the aerodynamic coefficients on the vertical position of the second louver.

Since these preliminary experimental results show that the most critical position is the windward one, the experimental effort was concentrated in the analysis of isolated louvers.

\section{Conclusions}

In previous works the dependence of the galloping stability on the cross-sectional geometry and the angle of attack has been proved for cylinders with different cross-sections. It has also been demonstrated that the Glauert-Den Hartog criterion for galloping instability, implemented with aerodynamic coefficients measured in static wind tunnel tests, is an appropriate tool to determine regions of instability with respect to the incident wind angle of attack and cross-section geometrical parameters.

Continuing this line of investigation, a cross-section which is very interesting from the civil construction point of view is the Z-profile. This type of geometry is employed in louvers and slats used as sun shading devices in buildings that incorporate glazed façades. Being very light structures they are susceptible to gallop.

This paper reports the results obtained in a systematic analysis performed on a family of $Z$-shaped crosssections, made out of a central web and two side wings to determine under which angle of attacks and geometrical parameters this type of profiles becomes unstable from a galloping point of view. Static wind tunnel experiments have been performed for such purpose. From the measured aerodynamic coefficients the $H(\varphi, \alpha, n)=\mathrm{d} c_{l} / \mathrm{d} \alpha+c_{d}$ functions have been determined and from them stability maps in the $n-\alpha$ plane have been plotted.

For the $\varphi=90^{\circ}$ family with wings normal to the central web, there is a clear instability region around $\alpha \approx 90^{\circ}$ for the different values of the geometrical parameter $n$, which gives an indication of the wings/ web relative length. Between $n=3$ and $n=6$ there is another instability region, narrower, for the angles of attack region between $\alpha \approx 20^{\circ}$ and $\alpha \approx 40^{\circ}$.

Streamlined profiles $\left(\varphi=45^{\circ}\right)$ are more stable, being the instability region for them around $\alpha \approx 45^{\circ}$ and only for geometries with the parameter $n>3$. These conclusions can be directly taken into consideration by designers of shading systems mounted in glazed façades to avoid potential translational galloping problems by choosing appropriately the geometry and the orientation of the louvers. The practical application of these results will be reinforced in future investigations where the effect of considering the louvers within an array and also the proximity of the building wall are considered.

Along the paper, the relationship between the appearance of galloping instability and the flow morphology around the cross-section is explained as well.

\section{Authors' Contribution}

All authors contributed equally in the preparation of this manuscript.

\section{Declaration of conflicting interests}

The authors declared no potential conflicts of interest with respect to the research, authorship, and/or publication of this article.

\section{Funding}

This research received no specific grant from any funding agency in the public, commercial, or not-for-profit sectors.

\section{References}

1. Datta G. Effect of fixed horizontal louver shading devices on thermal performance of building by TRNSYS simulation. Renew Energy 2001; 23: 497-507.

2. Kuhn TE. Solar control: comparison of two new systems with the state of the art on the basis of a new general evaluation method for facades with venetian blinds or other solar control systems. Energy Build 2006; 38: 661-672.

3. Tzempelikos A. The impact of venetian blind geometry and tilt angle on view, direct light transmission and interior illuminance. Solar Energy 2008; 82: 1172-1191.

4. Chaiyapinunt $S$ and Worasinchai S. Development of a mathematical model for a curved slat venetian blind with thickness. Solar Energy 2009; 83: 1093-1113.

5. Kim JJ, Jung SK, Choi YS and Kim JT. Optimization of photovoltaic integrated shading devices. Indoor Built Environ 2010; 19: 114-122.

6. Palmero-Marrero AI and Oliveira AC. Effect of louver shading devices on building energy requirements. Appl Energy 2010; 87: 2040-2049.

7. Saelens D, Parys W, Roofthooft $J$ and de la Torre AT Assessment of approaches for modeling louver shading devices in building energy simulation programs. Energy Build 2013; 60: 286-297. 
8. Lim HS and Kim G. Predicted performance of shading devices for healthy visual environment. Indoor Built Environ 2010; 19: 486-496

9. Kim JT, Shin JY and Yun GY. Prediction of discomfort glares from windows: influence of the subjective evaluation of window views. Indoor Built Environ 2012; 21: 92-97.

10. Shin HY, Kim G and Kim JT. Effect of occupants' behaviour of daylight controls on residential visual environment. Indoor Built Environ 2013; 22: 191-202.

11. Pérez-Grande I, Meseguer J and Alonso G. Influence of glass properties on the performance of double-glazed façades. Appl Thermal Eng 2005; 25: 3163-3175.

12. Argiriou AA, Balaras CA and Lykoudis SP. Single-sided ventilation of buildings through shaded large openings. Energy 2002; 27: $93-115$.

13. Tablada de la Torre AE, Saelens D, Carmeliet J and Baelmans M. Investigation on airflow and heat transfer of a glazing façade with external louvers. Proceedings of the 4th International Building Physics Conference. Istambul, June 2009, pp.877-884.

14. Diemling A, Krönke I, Schramke F and Sockel H. Wind-induced vibrations of a façade element. $J$ Wind Eng Ind Aerodyn 1983; 11 : 133-148.

15. Wood CJ. The effect of lateral vibrations on vortex shedding from blunt-based aerofoils. J Sound Vib 1971; 14: 91-102.

16. Kim JT and Kim G. Advanced external shading device to maximize visual and view performance. Indoor Built Environ 2010; 19 : $65-72$.

17. Den Hartog JP. Mechanical vibrations. 4th ed. New York: McGraw-Hill, 1956.

18. Novak M. Aeroelastic galloping of prismatic bodies. ASCE J Eng Mech Div 1969; 96: 115-142.

19. Novak M. Galloping oscillations of prismatic structures. ASCE J Eng Mech Div 1972; 98: 27-46.

20. Novak $M$ and Tanaka $H$. Effect of turbulence on galloping instability. ASCE J Eng Mech Div 1974; 100: 24-47.

21. Alonso G, Sanz-Lobera A and Meseguer J. Hysteresis phenomena in transverse galloping of triangular cross-section bodies. J Fluids Struct 2012; 33: 243-251.

22. Alonso $\mathrm{G}$ and Meseguer J. Hysteresis phenomena in aerodynamics. In: Dias JC (ed.) Hysteresis: types, applications and behavior patterns in complex systems. New York, NY: Nova Science Publishers, 2014.

23. Hémon $\mathbf{P}$ and Santi F. On the aeroelastic behaviour of rectangular cylinders in cross-flow. J Fluids Struct 2002; 16: 855-889.

24. Blevins RD. Flow-induced vibrations. 2nd ed. Malabar, FL: Krieger Publishing Co., 1990.

25. Naudascher E and Rockwell D. Flow-induced vibrations: an engineering guide. Rotterdam: A.A. Balkema, 1994.

26. Alonso G, Meseguer J and Pérez-Grande I. Galloping oscillations of two-dimensional triangular cross-sectional bodies. Exp Fhids 2005; 38: 789-795.

27. Alonso G and Meseguer J. A parametric study of the galloping instability of triangular cross-section bodies. $J$ Wind Eng Ind Aerodyn 2006; 94: 241-253.

28. Alonso G, Meseguer J and Pérez-Grande I. Galloping stability of triangular cross-sectional bodies: a systematic approach. $J$ Wind Eng Ind Aerodyn 2007; 95: 928-940.

29. Alonso G, Valero E and Meseguer J. An analysis on the dependence on cross section geometry of galloping stability of twodimensional bodies having either biconvex or rhomboidal cross sections. Eur J Mech B Fluids 2009; 28: 328-334.
30. Alonso G, Meseguer J, Sanz-Andrés A and Valero E. On the galloping instability of two-dimensional bodies having elliptical cross sections. J Wind Eng Ind Aerodyn 2010; 98: 438-448.

31. Ibarra D, Sorribes F, Alonso G and Meseguer J. Transverse galloping of two-dimensional bodies having a rhombic cross-section J Sound Vib 2014; 333: 2855-2865.

32. Abbott IH and Von Doenhoff AE. Theory of wing sections New York: Dover Publications Inc., 1959.

33. Ayuso L, Sant R and Meseguer J. Influence of leading edge imperfections on the aerodynamic characteristics of NACA $63_{2} 215$ laminar aerofoils at low Reynolds number. Proc IMechE, Part G: J Aerospace Engineering 2014; 228: 859-868.

\section{Appendix 1}

To evaluate the influence of the façade on the wind loads on a set of louvers, a simple louver configuration has been tested in the A9 wind tunnel of IDR/UPM. The tested configuration consists of five two-dimensional elliptical louvers subjected to a smooth flow as already described previously. From the five louvers, only the central one is instrumented. This central louver is equipped with 34 pressure taps, 16 in the upper side, 16 in the lower side, plus another two located at the trailing and at the leading edge, respectively. The louvers chord is $0.2 \mathrm{~m}$, and the maximum thickness $0.02 \mathrm{~m}$. Louvers can be rotated around their centres, the vertical distance between the axes of rotation of two adjacent louvers being $0.09 \mathrm{~m}$. As sketched in Figure 14, the air can freely flow through the louvers set (configuration $\mathrm{A}$ ) or the flow is blocked by a wall located behind the louvers whose height is $0.8 \mathrm{~m}$ (configuration B). The horizontal distance between the plane defined by the louver axes and the wall is $0.2 \mathrm{~m}$.

Once the angle of attack of the louvers is set, the wind tunnel is switched on and the pressure distribution on the instrumented louver is measured. From measured pressures the pressure coefficient distributions are obtained as explained, and the force coefficient in the direction of the airfoil chord, $c_{i}$, and in the normalto-chord direction, $c_{n}$, results, as well as the pitching moment at the rotating axis. These coefficients are illustrated in Figure 14.

Measured results are depicted in Figure 14. It must be stressed that the presence of a façade behind the louvers drastically reduces the wind loads, the reason being that such a façade causes the stagnation of the flow at the façade surface, thus reducing the velocity of the flow close to the louvers set. 


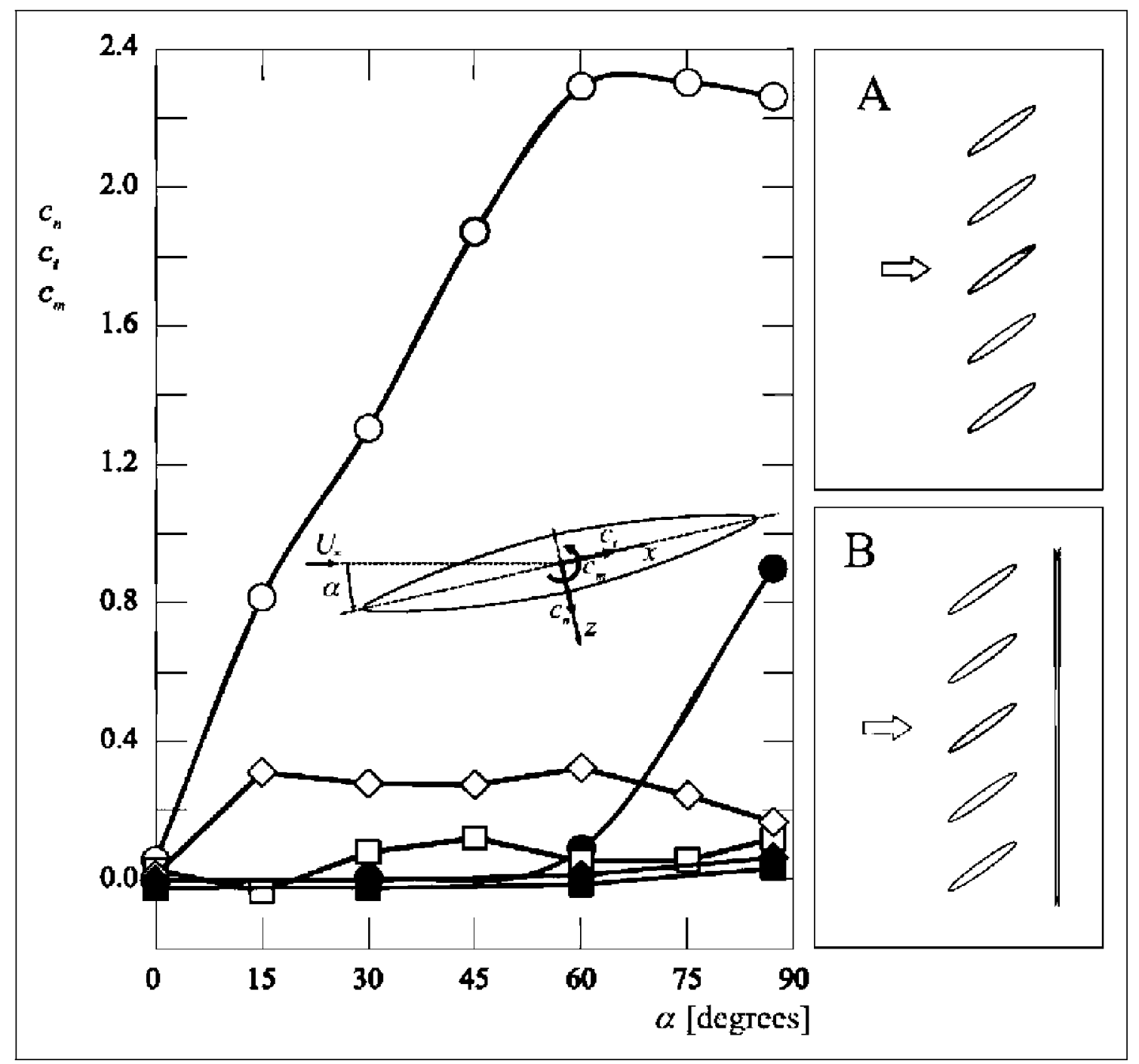

Figure 14. Variation with the angle of attack, a, of the wind loads acting on the central louver of a louver set arranged as indicated in the sketches: normal force coefficient, $\mathrm{c}_{\mathrm{n}}$ (circles); chord direction force coefficients, $\mathrm{c}_{\mathrm{t}}$ (squares) and pitching moment, $\mathrm{c}_{\mathrm{m}}$ (rhombi). White symbols correspond to configuration $\mathrm{A}$ (without any solid surface behind the louvers), whereas black symbols indicate configuration B (with a solid surface behind the louvers). 